\title{
Acessibilidade Móvel para Alfabetização de Deficientes Visuais: Proposta Inicial de um Protótipo
}

\author{
Jenifer Melissa de Paula ${ }^{1}$, José Valter Amaral de Freitas ${ }^{1}$, Thatiane de Oliveira \\ Rosa $^{1}$ \\ ${ }^{1}$ Curso de Gestão da Tecnologia da Informação - Campus Paraíso do Tocantins do \\ Instituto Federal de Educação, Ciência e Tecnologia do Tocantins (IFTO) \\ Distrito Agroindustrial, BR 153, KM 480 - Caixa Postal 151 - 77.600-000 - Paraíso do \\ Tocantins - TO - Brasil \\ \{jenifermelissadep, josewalteraf\}@gmail.com, thatianelifto.edu.br
}

\begin{abstract}
According to the 2010 census, 18.8\% of the population has visual impairment, and such portion requires special attention in several respects, especially with regard to the educational process. Another relevant fact is that today information technology is used as a support for execution of several processes, including the teaching/learning, which extends the possibilities of interaction. a trend towards adoption of mobile technologies being perceived. Therefore, this work aims to identify desirable requirements for a mobile application touch screen, aimed assist in literacy visually impaired.
\end{abstract}

Resumo. De acordo com o censo de 2010, 18,8\% da população brasileira possui deficiência visual, sendo que tal parcela necessita de atenção especial em diversos aspectos, principalmente no que tange ao processo educativo. Outro fator relevante é que hoje a tecnologia da informação é utilizada como suporte para execução de diversos processos, dentre eles o de ensino/aprendizagem no qual amplia as possibilidades de interação. Sendo percebida uma tendência à adoção de tecnologias móveis. Diante disso, esse trabalho possui como objetivo identificar requisitos desejáveis a uma aplicação móvel touch screen, que vise auxiliar a alfabetização de deficientes visuais.

\section{Introdução}

A aplicação de novas práticas didáticas aliadas a recursos tecnológicos diversos vêm ampliando as possibilidades de ensino em diversas áreas. Desse modo, essas práticas têm sido muito úteis para a educação, pois os conteúdos podem ser abordados de várias formas tais como imagens, vídeos, hipertextos, animações, simulações, jogos educacionais, páginas web, entre outras. Esses métodos servem como incentivo e ferramenta para práticas pedagógicas mais criativas, inovadoras e eficazes, proporcionando novas maneiras de pensar e de manifestar ideias, tanto sobre educação, quanto sobre comunicação, tecnologia e interação com a realidade (BEHAR; TORREZAN, 2009).

Em harmonia com esse contexto, surgiram os "nativos digitais" ou "geração multitarefa", que segundo Tori (2010) são crianças, adolescentes e jovens que nasceram na era da internet, que estão conectados ao mundo e que sem sair de casa, conseguem 
estudar, fazer pesquisas na internet, conversar com os amigos e assistir a programas televisivos simultaneamente. Eles conseguem absorver e descartar grande quantidade de informações e exercer atividades paralelas, no entanto precisam ser frequentemente motivados e recompensados. A partir das considerações desse mesmo autor, entende-se que uma criança, adolescente ou jovem com deficiência visual atende pelas mesmas características.

Diante disso, ao considerar que $18,8 \%$ da população brasileira possui deficiência visual (IBGE, 2010), e que tal parcela necessita de uma atenção especial no processo educativo, visto que possuem algumas limitações, mostra-se importante realizar um estudo que aborde o viés educação de deficientes visuais apoiada por tecnologia da informação, por meio de dispositivos móveis.

Nesse contexto, com relação à tecnologia, existem aplicações de acessibilidade em diversos ambientes digitais, como páginas web, desktops e dispositivos móveis. Entretanto, de acordo com a pesquisa bibliográfica realizada até o momento neste trabalho, existem aplicações móveis que auxiliam na alfabetização, entretanto as mesmas não são desenvolvidas para atender às necessidades apresentadas pelos deficientes visuais. Dentre as aplicações móveis existentes para auxiliar na alfabetização, porém, não voltadas aos deficientes visuais, pode-se citar a m-EQUIV, que tem a finalidade de apoiar o ensino de leitura para crianças (SILVA; PINHEIRO, 2014). Logo, a área de aplicações móveis para deficientes visuais ainda é pouco explorada, possuindo assim recursos, informações e conhecimento limitados.

Diante do contexto apresentado, a área de aplicações móveis voltadas à acessibilidade visual é de extrema importância para a sociedade, não apenas pelo valor tecnológico, mas também pelos valores sociais e culturais. Portanto, a partir desse cenário, vê-se a necessidade de realizar uma pesquisa científica que tenha como objetivo identificar os requisitos desejáveis para desenvolver uma aplicação móvel touch screen, que vise auxiliar a alfabetização de deficientes visuais.

\section{Metodologia}

A pesquisa a ser realizada neste trabalho pode ser classificada como exploratória e qualitativa, pois visa uma investigação por meio de estudos bibliográficos, entrevistas e análises de ambientes reais, para que a partir da interpretação das informações coletadas possam ser identificados os requisitos desejáveis à aplicação pretendida. Conforme ilustra a Figura 1, a pesquisa é composta por três fases: Pesquisa Bibliográfica, Estudo de Campo e Prototipagem.

A primeira fase consiste na realização de uma pesquisa bibliográfica simples direcionada à investigação de conceitos relacionados à acessibilidade, deficiência visual e suas leis, metodologias de alfabetização de crianças com deficiência visual, e utilização da TI no processo educacional.

A fase 2 consiste em um estudo de campo, o qual tem como objetivo identificar as principais dificuldades no processo de alfabetização de crianças com deficiência visual, e a partir disto ser possível projetar soluções tecnológicas. O estudo de campo será realizado com base em entrevistas com envolvidos no processo de alfabetização, 
com familiares, professores e estudantes. Além de observação e acompanhamento do cotidiano do processo de alfabetização de crianças com deficiência visual.

Por fim, a fase 3 tem o objetivo de desenvolver um protótipo de alta fidelidade de uma aplicação móvel para a alfabetização de deficientes visuais, elaborada com base nos conceitos estudados durante a fase 1 , e nas informações obtidas na fase 2 .

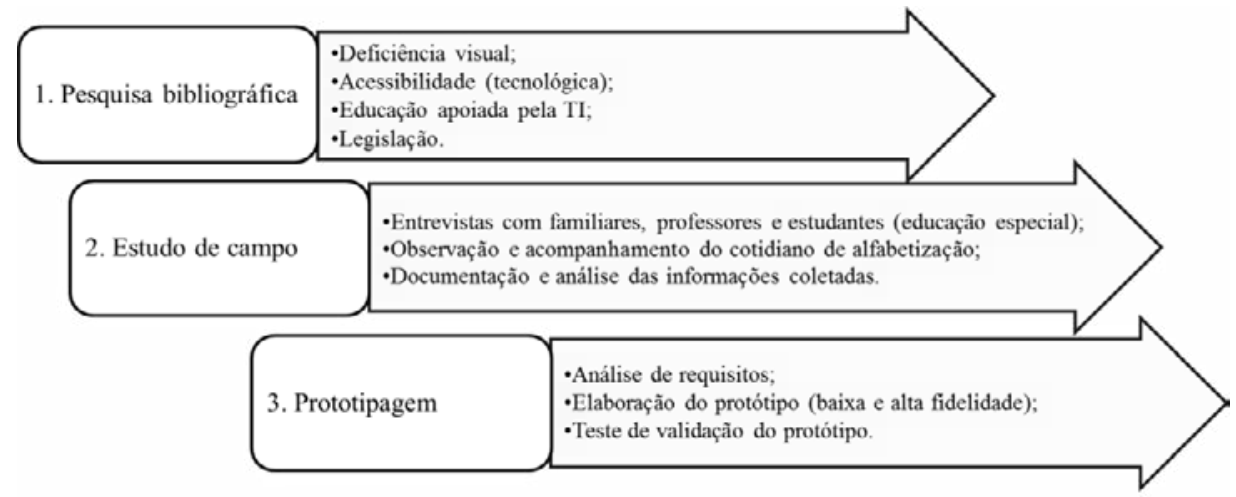

Figura 1. Fases da metodologia.

Até o momento, através da pesquisa bibliográfica foi desenvolvida uma primeira versão do protótipo, levando em consideração as normas e requisitos de desenvolvimento de software acessível identificados na pesquisa, e baseando-se também em softwares e jogos que possuem características semelhantes e favoráveis ao projeto, porém, que possuem outros objetivos. Vale ressaltar que a fase 2 está em plena execução.

\section{O Protótipo}

O objetivo dessa primeira versão do protótipo é servir de base para o estudo de campo (segunda fase), sendo apresentado aos profissionais da educação especial para avaliação e sugestões, juntamente com um questionário sobre as metodologias de ensino especial, suas dificuldades e necessidades. Após análise e avaliação das sugestões e dos resultados do questionário, além dos requisitos já levantados, será desenvolvida uma segunda versão do protótipo, obedecendo todas as considerações feitas até o momento (terceira fase).

O protótipo será uma espécie de jogo interativo, onde a criança deverá aprender as letras do alfabeto, fazendo associação de cada letra a um objeto ou coisa, através do som produzido por ele, com a letra "c", por exemplo, seria um "carro", que produz um som único "Vrum vrum". O jogo simulará um tabuleiro, onde cada parada representa uma letra. A criança deve ouvir o som e fazer associação da letra com o objeto que a representa.

A comunicação entre a criança e o jogo será feita através de comandos de voz e de toques na tela, onde o jogo "conversa" com a criança e a faz perguntas. Para iniciar a interação, a criança precisará apenas manter o dedo pressionado na tela para responder cada uma das perguntas apresentadas. A arquitetura de funcionamento proposto é ilustrada na Figura 2. 


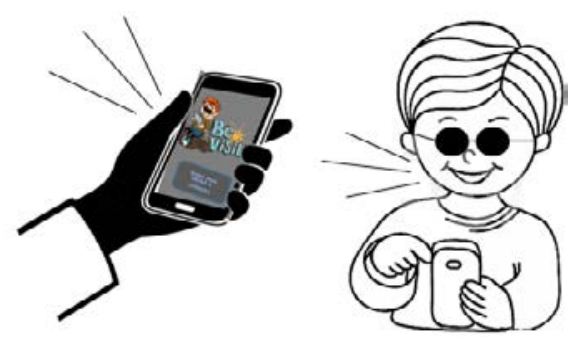

Figura 2. Arquitetura de funcionamento.

Os requisitos identificados até o momento para o jogo foram os seguintes: Entrar no Jogo, Salvar Jogo, Sair do Jogo, Iniciar Fase, Reiniciar Fase, Avançar Fase, Encerrar Fase, Escutar Desafio, Responder Desafio, Configurar Personagem, Apresentar Orientação e Acionar Ajudar. Tais requisitos são ilustrados através do diagrama de casos de uso da Figura 3.

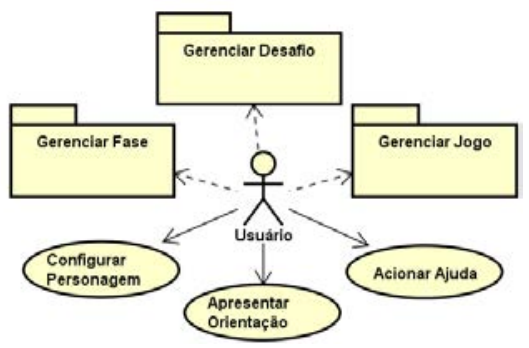

Figura 3. Diagrama de Caso de Uso.

Conforme citado anteriormente, os estudos ainda não foram finalizados, sendo este apenas o início dos resultados alcançados até o momento. A partir dos quais buscase fomentar discussões acerca do uso das tecnologias móveis no processo de alfabetização de crianças com deficiência visual.

\section{Referências}

BEHAR, Patrícia Alejandra; TORREZAN, Cristina A. W. Parâmetros para a construção de materiais educacionais digitais do ponto de vista do design pedagógico. In: BEHAR, Patrícia Alejandra (Org). Modelos Pedagógicos em Educação a Distância. Porto Alegre: Artmed, 2009. P.33-65.

IBGE - Instituto Brasileiro de Geografia e Estatísticas. Censo 2010. Disponível: $<$ www.ibge.gov.br/home/presidencia/noticias/imprensa/ppts/0000000935250612201225 5229285110.pdf>. Acesso em 22 fev. 2015.

SILVA, Roberto A. D., PINHEIRO, Edson Pinheiro. Proposta de Aplicativo em Dispositivos Móveis para Ensino de Leitura Baseado no Controle por Unidades Mínimas. Universidade Federal do ABC (UFABC) Santo André - SP - Brasil, 2014. Disponível em: <www.tise.cl/volumen10/TISE2014/tise2014_submission_140.pdf> Acesso em 20 mai. 2015.

TORI, Romero. Educação sem distância. As tecnologias interativas na redução de distâncias em ensino e aprendizagem. São Paulo: Editora SENAC São Paulo, 2010. 